\title{
Lunar-sourced GEO Powersats: An Integrated ISRU System
}

\author{
Peter J. Schubert, Ph.D., P.E., Richard J. Anderson III, Alex Somera, Patrick Proctor, \\ Yung Wei Chin, Jonathan Bowyer, Nathan McIntyre, Tyler Jackson \\ IUPUI, Indianapolis, IN 46202
}

\begin{abstract}
Solar power satellites (powersats) can be built almost entirely from lunar resources. When C-class asteroids are also included as ore bodies a complete powersat can be built through in situ resource utilization (ISRU) given appropriate processing and transportation technology. This article provides an in-depth overview of the technical feasibility and economic viability of lunar construction and operations for powersat component construction and delivery to geostationary earth orbit (GEO). Techno-economic analysis suggests a return on investment in seven years assuming a three percent discount rate. Electrical power collected in GEO and beamed to terrestrial receivers by the powersats can be sold as baseload power in the wholesale electricity market to generate revenue. This work presents a complete concept of operations from initial rocket launches to regolith harvesting through transport to GEO. Lunar infrastructure can be constructed of modules to optimize size and weight for launch costs. Future growth can be derived from using ISRU to build additional processing bases. A scaleup in this manner can provide $22 \%$ of the world's energy needs by the end of a 20 -year period. This work builds upon previous studies and completes the architectural description of predominantly lunar-sourced GEO powersats.
\end{abstract}

\section{Introduction}

$\mathrm{E}$ nergy generation technologies for baseload power with renewable sources and minimal pollution are currently intermittent when compared to traditional non-renewable energy sources such as petroleum fuels and coal. Wind and solar energies are not sufficiently reliable on their own, and cannot be predicted accurately. This issue can be mitigated with large-scale storage (currently very expensive) or if sources such as energy from the sun were stable, consistent, and constant. Space Solar Power is a solution to the intermittent nature of renewables implemented via Solar Power Satellites (SPS or powersats). Powersats would require significant amounts of non-renewable terrestrial energy resources if constructed and launched into orbit from Earth. Lunar-sourced materials have the advantage of reducing the total energies necessary to launch materials into Geostationary Earth Orbit (GEO) through the leverage of launching factories employing In-Situ Resource Utilization (ISRU). To realize these a suitable lunar architecture is needed which extracts and manufactures the necessary materials for producing multiple SPS installations. These lunar manufacturing strongholds can generate and recycle every necessary material for self-sufficiency plus SPS component production and delivery. Electromagnetic launches of lunar resources to Earth-Moon L1 can provide an attractive solution to the construction costs involved with SPS generation. The optimal places for lunar bases regarding power availability include the "Peaks of Eternal Light". Upon further analysis, the conditions seem to make Mt. Malapert the optimal site for a first moon base with the purposes discussed herein.

Accomplishing ISRU in a lunar environment warrants an integration of diverse capabilities working in concert to produce the necessary products for SPS. The first step is regolith collection via rover technology scaled up to acquire massive amounts of the lunar dust and soil for element extraction. Once collected, volatiles from within the lunar dust can be liberated by heat and captured for their value, then oxygen can be separated by electric resistance heating and radio-frequency coupling, followed by plasma ionization with byproducts of iron, silicon, aluminum, and a leftover refractory material termed "slag" 1,2,3,4. The silicon collected by separation can be fabricated into functional solar panels using trace dopant materials (e.g. phosphorus) from the regolith as well as aluminum for wiring and for structure. Collected iron can be fashioned into "payload canisters" for the purpose of electromagnetic propulsion of finished goods to the orbital Earth-Moon L1 halo point facility having the capability to receiving these payloads electromagnetically, studied previously. ${ }^{5}$

This is the author's manuscript of the article published in final edited form as: 


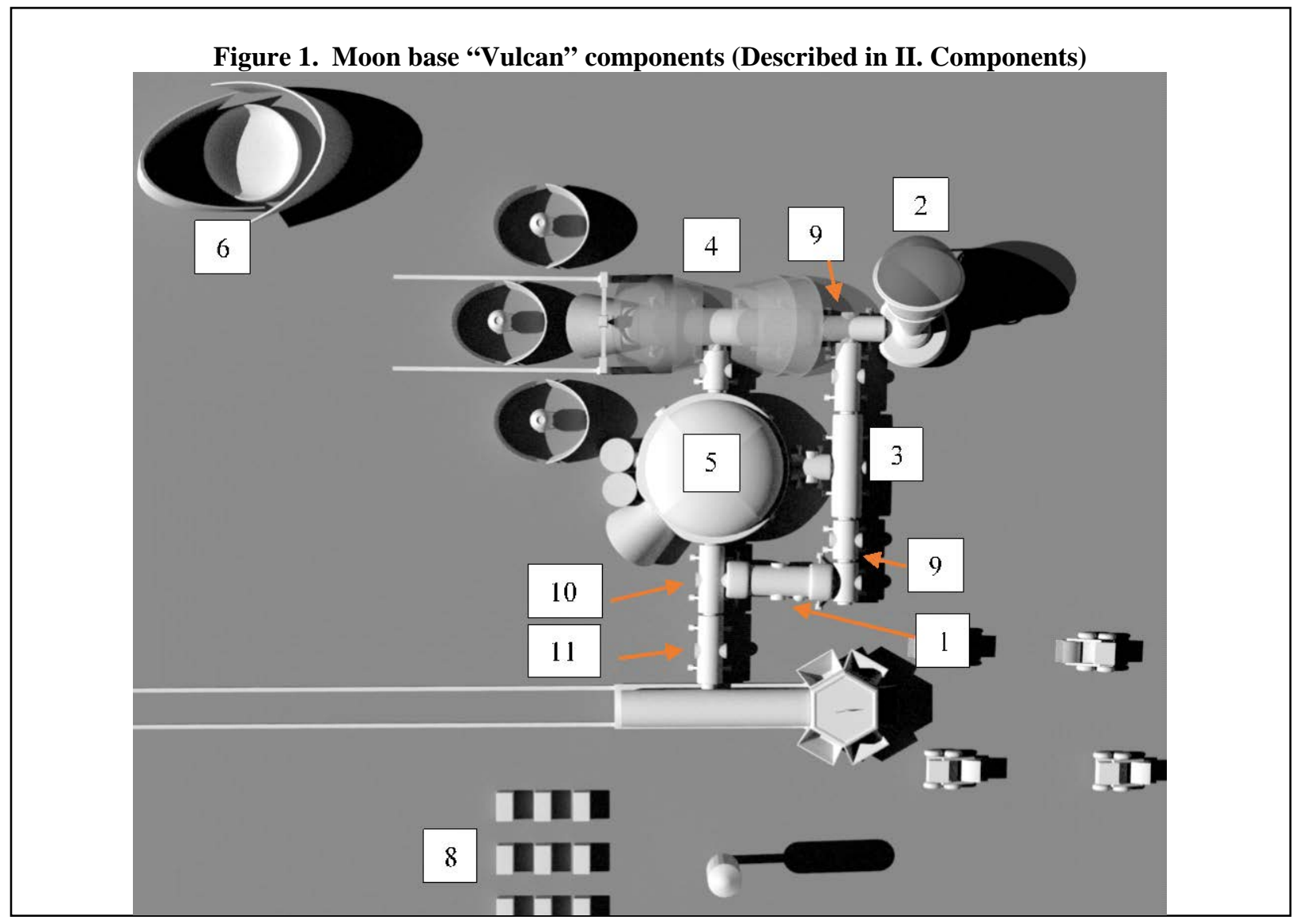

\section{Components}

\section{A. Lunar Facility (Referencing Figure 1)}

1. Dormitory and Canteen, and Cupola Module $\left(126 \mathrm{~m}^{3}\right)$

These are modeled after International Space Station (ISS) sections, adapated for lunar gravity (1/6 g). The cupola aboard this module acts as a window back home so an astronaut's private time can be spent in reflection, relaxation, and awe of the universe.

\section{Greenhouse $\left(400 \mathrm{~m}^{3}\right)$}

Novel features of the greenhouse include a structure which is represented in Figure 1 as a half dome atop a cone. The dome is translucent to admit and distribute diffuse light from any direction. This should allow near earth-like lighting conditions to be present at most times in the greenhouse.

3. Life Support $\left(126 \mathrm{~m}^{3}\right)$

Human long-term survival in lunar gravity environments has not been tested and requires careful consideration for development of the lunar surface. For astronauts to thrive, specific modules modified from ISS predecessors and additional life support modules are necessary components of a functional lunar base. Emergency prevention or response mechanisms are needed, such as: intelligent monitoring, and failsafe or redundant machinery to maintain pressures, healthy air concentrations, and which filters and recycles water and waste materials. Astronauts undergo osteoporosis during extended periods of weighlessness ${ }^{6}$ and will likely need vigorous exercise to remain healthy in a low-gravity environment. All necessary life support systems are assumed to run on $100 \mathrm{~kW}$ comparable to the International Space Station and allowing for a max crew of 13 based on the ISS historical maximum ${ }^{7,8}$.

\section{Central Command $\left(491 \mathrm{~m}^{3}\right)$}

Figure 1 depicts a translucent hyperboloid shell over the Central Command module, Auxiliary Landing, and three Soyuz pods. This recurring shell is an easily 3-D printed shape which can be layered atop the base to protect it from harmful ionizing radiation. The same shape can be placed around the landing pads to mitigate high-velocity dust spread in the low-gravity environment, as dust can be damaging to seals and to solar panels. ${ }^{9}$ A byproduct of isotope 
separation is a stream of insulating slag material. Using this effluent stream like a 3-D printer ${ }^{3}$ (claim 6 of the patent), structures can be manufactured for: lunar expansion to other bases; shed-like structures for storage; protective shields for structures and airlocks; and many other objects for structural purposes.

\section{Central Annex Landing $\left(393 \mathrm{~m}^{3}\right)$}

A common issue for lunar missions is the abrasive dust accumulated on space suits and machinery which grinds into the moving parts and can cause failures. In order to mitigate this issue, a "double membrane" technique for landing is envisioned. The technique involves the opening and closing of two separate dome hatches above the central landing, similar to an airlock. The inner dome should always be closed after the outer dome and always opened before the outer dome. In this way, dust does impinge on the inner dome and pressurization can be achieved. The outer dome (nonpressurized) exists to protect the inner dome and the structure from ionizing radiation. Furthermore, if pressurization is not available in the central landing, a tube connection system inspired by Weir's book Artemis can allow un-suited transfer of humans through the structure and into other connected modules of the lunar base. The central landing provides a location for safe and easy restocking of either the lunar facility or the visiting spacecraft. Furthermore, it reduces dust accumulation on solar panels and other machinery due to landing spacecraft.

\section{Auxiliary Landing}

Not every craft landing on the moon will be able to perform a landing at the central landing pad. Thus, auxiliary landing sites can be created with 3-D printing. Each site consists of a smooth disk structure clear of lunar dust to land on as well as blast shields to mitigate dust distribution via high-velocity particles. The hyperboloid shields should allow for the collection of dust which would have otherwise been launched up to $3 \mathrm{~km}$ from the landing pad. ${ }^{10}$ Dust suppression is important due to a large number of solar panels surrounding the proposed base.

\section{Gauss Cannon}

A primary component of the lunar facility in the ISRU capacity is the ability to transfer objects to GEO. To do this, the lunar facility is designed to transfer 50 kg payloads to the Earth-Moon L1 orbit where a separate station will collect the payloads and arrange them in L1 halo orbits until aggregation for transfer to GEO. This transfer to EarthMoon L1 is done via electromagnetic launching of a spherical iron payload canister filled with solar panels, aluminum wires, and slag targets derived from lunar regolith ${ }^{27}$. The Gauss cannon is emplaced atop a man-made hill having a loading mechanism which takes advantage of the limited gravity and the spherical nature of the payloads. Iron rails provide a pinball-like loading scheme. Underneath the man-made hill rests the ultracapacitor (UC) farm powering the cannon. This configuration allows the use of non-space-rated UC's under the protection of 2+ meters of regolith. Once electromagnetically launched and shuttled to GEO, the payloads can be used to construct powersats.

Additional modules depicted in Fig 1 include 8. Energy Production and Storage, including fuel cells, hydrogen storage, and battery storage; 9. Specialized Storage, Biomedical Research, and Agricultural Research Module; 10. Recycling Module where metals, glass, plastic, and organic materials are converted into useful materials for fabricating new parts, 3D printing, agriculture, and energy storage; and 11. Replacement Parts Production and Development Module where the materials from module 10 are up-converted.

\section{B. Regolith Collection}

To harvest and process regolith, at least two modules are necessary. The first, hexagonal module acts as a receptacle and grinding operation for particle size management regarding input to the isotope separator and delivers comminuted product to the second module for the manufacturing process. A first notable feature is the ability to employ iron from the isotope separation to manufacture rails along which future collection modules can travel to reach fresh sources of regolith. Alternatively, solar panels fixed to movable manufacturing modules could provide energy for continued manufacturing while utilizing mobility to follow sunlight around the curvature of the moon ${ }^{2}$. A second notable feature of the manufacturing modules is the use of a Thermal and Solar-Thermal Brayton Cycle ${ }^{11}$, using the heat produced by fresh slag from the isotope separation process, to reclaim and recycle heat energy to increase efficiency. This process could be enhanced using supercritical gases such as carbon dioxide ${ }^{12}$ and possibly the addition of a rotary engine such as the Wankel ${ }^{13}$ in place of a turbine to mitigate both mass considerations for launch costs as well as heat dissipation.

Schubert $e t a l^{1}$ assumes a batch of collected regolith to be 6 metric tons used for the optimal processing of the regolith. One batch is defined as the amount estimated to maximize the efficiency of the hexagonal Regolith Processing Module (pictured in Figure 1), a collection center with 5 deposit slots which will allow for continual input of regolith from the mining rovers and a long body of regolith processing machinery. The surface area of the moon necessary to collect 6 metric tons determined by the density and depth of the regolith.

Heiken et al. find regolith to be "about 4-5 m thick in the mare areas but may average about 10-15 $\mathrm{m}$ in older highland regions." ${ }^{14}$ According to a NASA study, the density of the regolith is $1.5 \mathrm{~g} / \mathrm{cm}^{3}$, which converts to 1,500 $\mathrm{kg} / \mathrm{m}^{3}{ }^{15}$ Deep regolith is an advantage for the lunar base envisioned herein. Energy requirements and resource 
depletion rates depend on solar availability. Due to this issue, novel designs for the "lunar train system" ${ }^{2}$ were implemented to provide a mobile collection unit for payload preparation. In periods of extended darkness, the railings upon which the mobile modules run can be electrified like power lines to provide energy as needed. Alternatively, aluminum cables can parallel the length of the railings to provide extended range and power to the processing units. If hardline power is not sufficient, it can be augmented by Wireless Power Transfer (WPT), used to deliver energy from the GEO SPS to earth-based customers. WPT could provide power for mobile units in the Moon's shadows if rectenna design is factored into the structural components of the modules. A combination of WPT and hardline power transfers should allow for a mobile scaleup of ISRU in less than idea locations.

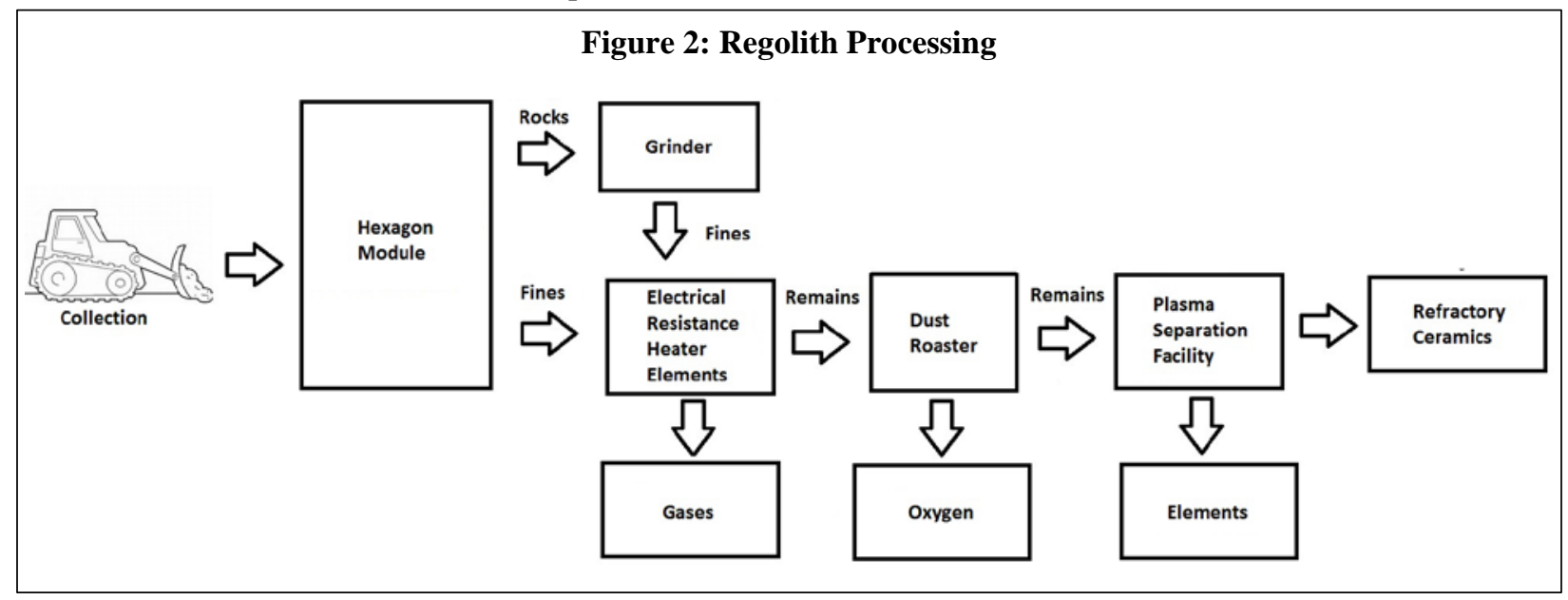

The process for regolith is shown in Figure 2. Regolith is first collected by one of the 6 rover miners powered by battery in a selected area. These rovers are estimated to collect $2.86 \mathrm{~m}^{3}$ of regolith every hour or $0.477 \mathrm{~m}^{3}$ for each rover. With a collection rate of $25067 \mathrm{~m}^{3} /$ year and an estimated regolith depth of 10 meters, such as in the highland regions, the rovers will only have to collect out to a radius of 28.2 meters within the first year of SPS production. Taking the weight of the regolith as well as the distance and height traveled into consideration, the estimated energy to collect a year's worth of regolith is $4.299 \mathrm{E}+08$ Joules. Converting to the power needed, assuming $10 \%$ efficiency from the rovers, 4.299E+09 Joules or $472 \mathrm{kWh}$ are necessary. This power translates to about 952 necessary batteries. Regolith is then taken to the hexagon module where the regolith is separated between fine dust and less fine rocks through vibration. Lunar harvesters are designed like bulldozers or front-end loaders to collect large amounts of regolith for processing. These harvesters are depictions of NASA-born Regolith Mining Rovers currently in test phases during the NASA Robotic Mining Competition. ${ }^{16}$ Following collection, the regolith is comminuted in the grinder/mill to a particle size acceptable for the machines coined the "Dust Roaster" and "Isotope Separator" under U.S. patents ${ }^{1,3}$. Once all the regolith particles are within dimensional tolerance, gases are extracted first as the fines are heated by electrical resistance heater elements (up to $1000 \mathrm{C}$ ). Oxygen is extracted next using rf induction heating (up to 2950 ${ }^{\circ} \mathrm{C}$ ) in the Dust Roaster. ${ }^{17}$ Elements are extracted last using plasma heating and separation by charge/mass ratio as described further below. ${ }^{3}$ The final remaining material from the processing is refractory ceramics used for radiation shielding and laser ablation targets. Electrical resistance heating followed by plasma ionization allows for the collection of individual elements (esp. Al, Si, Fe) comprising the lunar regolith and subsequent use of those elements for the construction of "payloads" in line with a previous study. ${ }^{18}$ Further in line is the assumption of a required 2.19E+06 payloads per SPS and, provided enough payload preparation modules outfitted with Dust Roasters and Isotope Separators, a feasible 10 Gigawatt gross producing powersat every 3 years. With proper scale-up described in Analysis, a return on investment (ROI) can be calculated and graphed for each post-investment year.

\section{Isotope Separation}

The lunar surface consists primarily of shattered and agglomerated minerals called regolith, entirely void of organic matter. The composition is dominated by oxygen followed by silicon and then metals such as iron, aluminum, and titanium. Of greatest interest is silicon for solar panels, aluminum for wires, iron for payload canisters to launch solar panels with the Gauss cannon, and of course oxygen for life support, propellant, and to make glass when combined with the silicon. Elements are separated by first forming a plasma beam which is divided into individual isotopes via a perpendicular electric field according to their charge-to-mass ratio. These ions will then be collected, neutralized, and repurposed. Non-ionized oxides of calcium and magnesium are formed into refractory blanks ("slag") to use as ablation targets for low-thrust propulsion and altitude control in space. ${ }^{19}$ To study isotope separation the 
program VSim (Tech-X) ${ }^{20}$ was used to study electron-impact (EI) ionization in a batch mode to approximate the

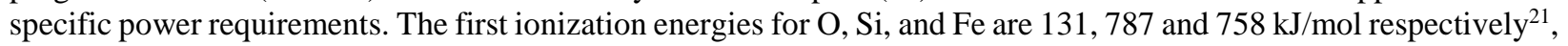
so the theoretical minimum energy to separate these critical elements is $53930 \mathrm{~kJ} / \mathrm{kg}$ at typical atomic abundances for lunar regolith. ${ }^{22}$

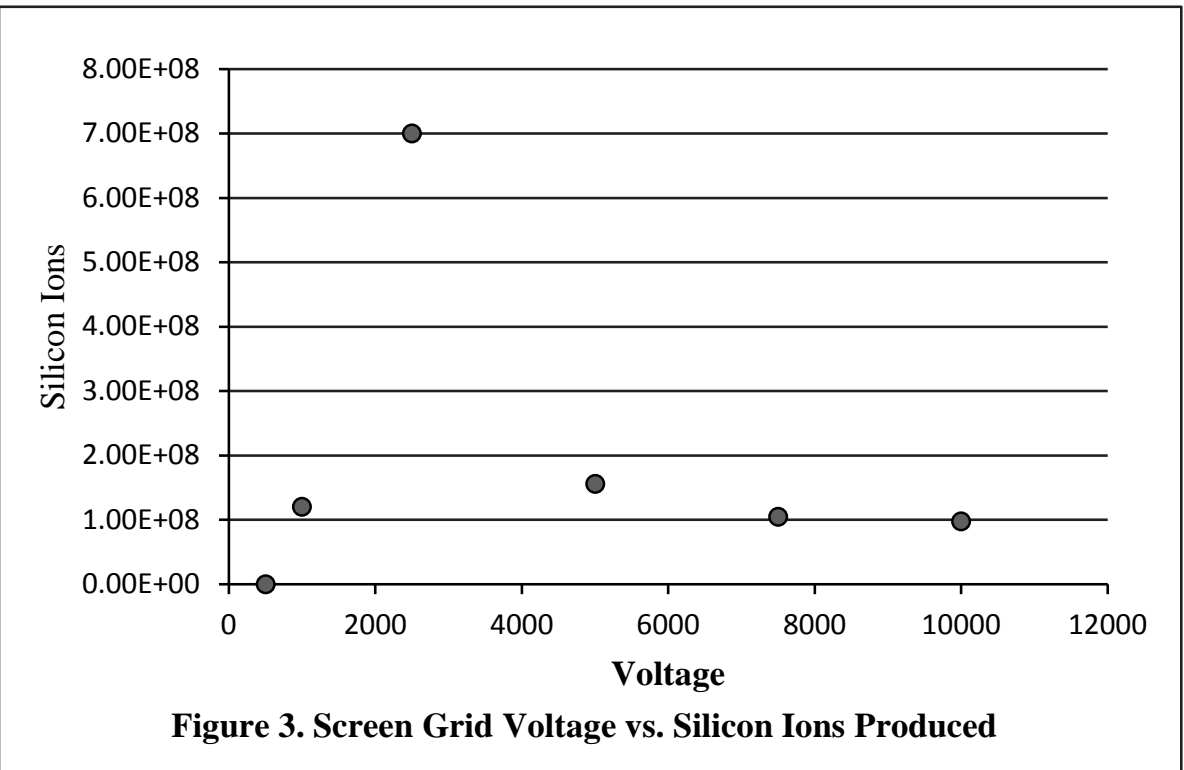

Accelerator grid voltages from 500 to 10,000 volts were studied with a maximum discovered at about $2500 \mathrm{~V}$ (see figure 3). The simulation was modeled after NASA's NEXT ion thruster ${ }^{23}$, with electron injection beam of 10 Amps, with average velocities for $\mathrm{O}, \mathrm{Si}, \mathrm{Fe}$ of 173000 , 133000 , and $93000 \mathrm{~m} / \mathrm{s}$. The VSim calculated specific energy is approximately 4E7 $\mathrm{kJ} / \mathrm{kg}$, compared to the theoretical value of 5.4E4, and represents a worst case. For this analysis, an intermediate value of 5E6 $\mathrm{kJ} / \mathrm{kg}$ was used. The number of particles in each batch was

5E8, and if the Deep Space 1 propulsions system is used as a data point for throughput is $1.24 \mathrm{E}-6 \mathrm{~kg} / \mathrm{s}$ of fuel consumption, representing a lower bound on throughput for isotope separation. At the other end of a range, an earlier study ${ }^{43}$ proposed $0.35 \mathrm{~kg} / \mathrm{s}$ for a range of between $1.3 \mathrm{E} 4$ and $1 \mathrm{E} 7 \mathrm{~kW}$. For this study, a value of $5 \mathrm{E} 6 \mathrm{~kW}$ per $\mathrm{kg} / \mathrm{sec}$ is used for isotope separation.

\section{L-1 Space Station}

A space station based on existing International Space Station hardware and construction techniques would be placed at the Earth-Moon L1 point. This station serves as a depot facility mid-way between the Earth and the Moon, redirecting lunar-launched payloads to halo orbits for temporary storage, and processing them for transfer from L1 to geostationary orbit on low-thrust tugs. The station itself will be constructed using solar arrays and pressurized modules derived from those used on the ISS. The physical arrangement of the station would be akin to the ISS with one major difference: a truss would extend from the station, perpendicular to both the modules and solar array truss. A powerful solenoid would be mounted to the end of this to redirect the lunar payloads with their ferrous spheres into halo parking orbits. ${ }^{24,25}$ The truss would need to be long enough to minimize the risk of accidental collisions with the solar arrays and pressurized segments. A crew of three will be aboard the station to oversee L1 operations. A crew escape vehicle will be docked at all times.

1. Halo orbit operations

Payloads launched from the lunar base via Gauss cannon should have a low arrival speed relative to the EarthMoon L1 point space station, thus requiring modest amounts of power for the solenoid to successfully redirect them. The station-mounted solenoids redirect payload canisters into a looping halo orbit for temporary storage while tugs are assembled and fitted with thrusters based on refractory slag included in the payload canister to be sent down-well to GEO. The practice of "juggling" these payloads in L1 would preclude the necessity of dedicated storage facilities on the station. Depending on the rate at which these payloads are received from the lunar surface and the rate at which they depart for GEO, a sizeable inventory could be stored in circulating halo orbits at L1. An earlier study ${ }^{24}$ used highpower solenoids in fly-by and pass-through configurations operating at high power to redirect similar payloads into GEO. Because of the much lower relative speeds involved in this study (assuming $<100 \mathrm{~m} / \mathrm{s}$ relative to the station), the power requirements of the solenoids on the space station can be much lower.

Assuming one half of the ISS' power generating capacity (100 kW) and 124 VAC voltage, required current is 200 amps for a 5-meter long solenoid with 400 turns per meter to generate a magnetic (B) field of about 0.1 Tesla using Equation (2) addressed in more detail below. Making half the power generating capacity of the ISS available to the L1 station was taken as a reasonable estimate, with the remainder used for station operations.

American Institute of Aeronautics and Astronautics 
The station will need enough battery storage capacity to continue operation when in the umbra of the Earth or the Moon. Taking the umbra to be a conical region behind both the Earth and Moon, the length of the lunar umbra to extend up to 378,000 km from the lunar core, and the Earth's umbra to extend up to 1.4 million km from the center of the Earth, the Moon's umbra extends up to 319,758 km from Earth-Moon L1 and 1.074 million km from the same point (see Table 3). Since the station will spend more time in Earth shadow than Moon shadow, it will need sufficient battery storage capacity to continue normal operations until the station reemerges from the umbra. These numbers assume that the station is passing through the center of the Earth's umbra rather than some off-center path, ensuring compensation for the longest-lasting eclipses.

Formula (1) calculates the opportunity cost of solar energy when the station goes into either the Earth's or the Moon's shadow. This formula was derived by treating both umbrae as conic regions based at the bodies' respective cores and trailing off into space. In this case, $\mathrm{P}$ is the power generated by the station in direct sunlight, $\mathrm{r}_{\mathrm{p}}$ is the radius of the body casting the shadow, $l_{u}$ is the length of the umbra, ls is the distance of the station from the body's core, and $\mathrm{V}_{\mathrm{L} 1}$ is the speed of the $\mathrm{L} 1$ point around the Earth.

Because the L1 point is between the Earth and the Moon, it can only be in the shadow of one of these bodies at a time. This would be a different situation for a station situated at L2 or L3, where one could occasionally experience concurrent shadows, passing from one umbra to another, which would increase the energy storage requirements for the space station. Thus, the worst-case scenario for passing through a shadow would be when the station passes through the exact center of the Earth's shadow. For all other instances of the station going into a shadow, it will follow a chordshaped path across the cross-section of the umbra. As shown in the table below, $312.8 \mathrm{kWh}$ of battery storage capacity would be required on-station to continue operations unaffected. Additionally, this is the worst-case scenario, the station passing through the exact center of the shadow.

$$
\text { Energy }=2 P r_{p} \frac{\left(l_{u}-l_{s}\right)}{l_{u} v_{L 1}}
$$

As there is no core in this solenoid, the permittivity of free space is used. One way to increase magnetic field strength and thereby reduce the power requirements of the solenoid is by adding a hollow iron core wide enough for the payloads to fly through.

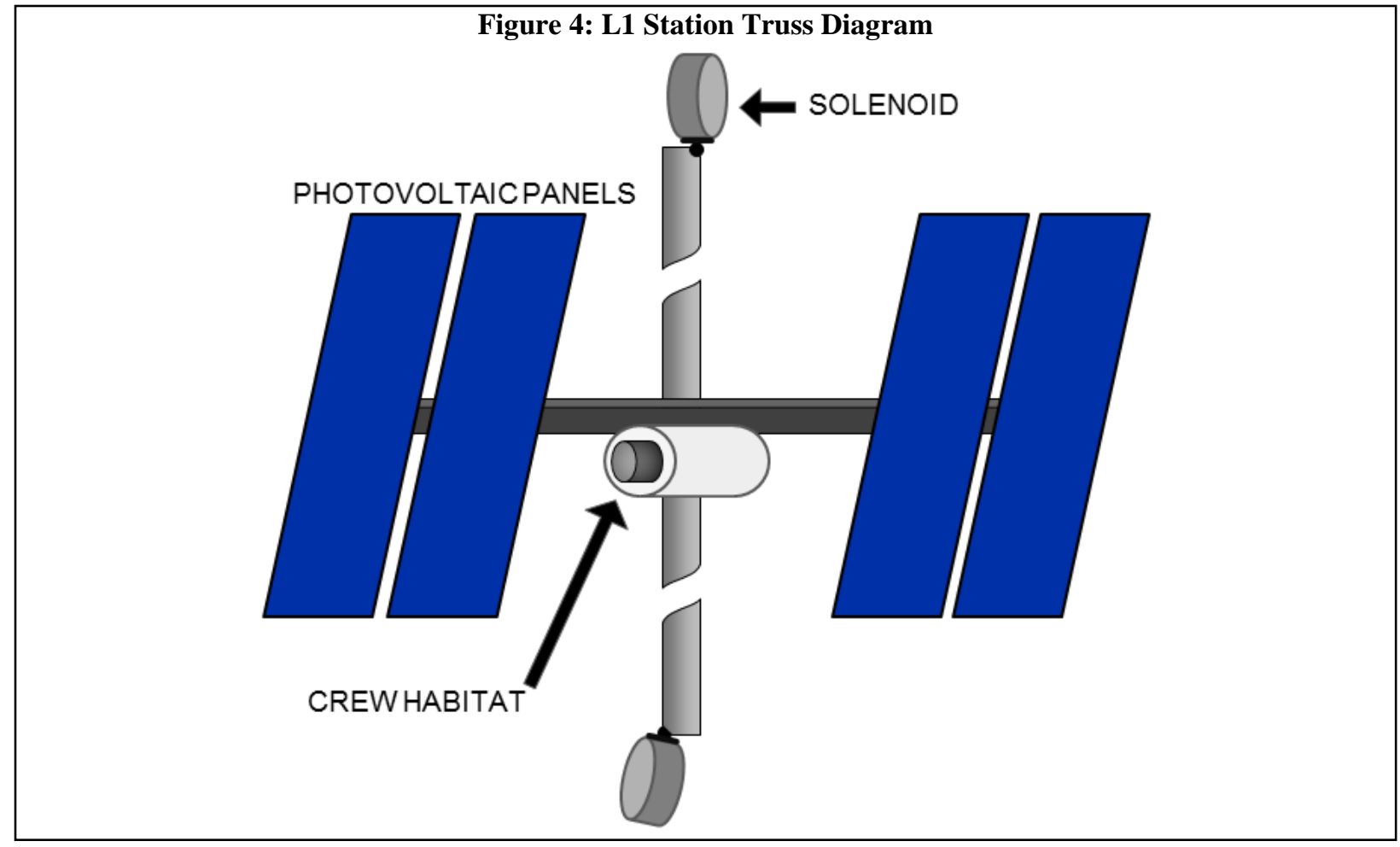

The basic arrangement of the station is similar to the ISS. There are multiple modules for the crew to live and work in. At a minimum, there will be a node, an ISS Destiny-style laboratory, and an ISS Quest-style airlock (Figure 4). 


\section{2. $\quad$ Docking ports (International Docking Standard)}

Two or three International Docking Standard (IDS) docking ports for visiting vehicles will be necessary. As this is to be the standard for spacecraft going forward, it should allow future American, Russian, Chinese, and other vehicles to dock.

3. Power Truss

A truss is attached to the top of the node and laboratory, at the top of the station. The truss contains power systems: $100 \mathrm{~kW}$ solar arrays, batteries, associated power hardware as well as inverters which convert DC input to 124 VAC for use on the station.

4. Solenoid Truss

$$
I=\frac{l B}{n \mu_{0}}
$$

Equation (2) is a special-case application of Ampère's circuital law that simplifies the basic operation of a linear solenoid, where $B$ is the magnitude of the magnetic field, $\mu_{0}$ is the permittivity of free space, $n$ is the number of turns per length of the solenoid, and $\mathrm{l}$ is the length of the solenoid. ${ }^{26}$ The solenoid truss is attached to the end of node opposite the power truss and contains the solenoid for attracting and slowing payloads after being launched from the lunar surface and redirects them into a parallel halo orbit for storage. This configuration should be enough to capture as many as nine $50 \mathrm{~kg}$ payloads per minute.

In this station configuration, up to 9.3 payloads and payload masses could be captured every minute after an average $\Delta \mathrm{v}$ of $100 \mathrm{~m} / \mathrm{s}$ is applied to slow them, equivalent to 293 million payload captures per year. This would make the constraining factor the rate at which these spherical payloads could be launched up from the Moon. This figure, however, is based on the notion that the solenoid would be doing nothing but catching a constant stream of payloads and not redirecting them. This can be accomplished via an additional solenoid of lower power not considered in this analysis.

Payloads launched from the lunar surface will be directed into temporary halo orbits until they can be sent downwell to geostationary orbit. Near-rectilinear halo orbits (NRHOs) take the form of highly elliptical orbits with low perilunes and a period of about six days. ${ }^{25}$ This would make it possible to have multiple "rings" or "cycles" of payloads with minimal chances of collisions. Careful redirection of payloads can be accomplished with free-flying drones or tugs that use the same ablative laser propulsion ${ }^{27}$ described below and the "fly-through" and "pass-through" solenoids described by Schubert et al. ${ }^{19,24,27}$ These could fly alongside the "swarm" of payloads, stabilizing their orbits or sending them to the station for processing. Power for these smaller spacecraft could be provided by a combination of photovoltaic solar arrays and beamed power from the station. Beamed power from the station would incur some efficiency losses but would save weight and complexity on the tugs. They would have to be sent out from L1 in a constant stream down to a facility or facilities in GEO. They would then be slowed down electromagnetically in a manner similar to the system described above. ${ }^{24}$

The force law as it is applied to lunar regolith has been explored. The solenoid would induce a magnetic field in the iron that would need to be accounted for. Formula (3) includes the magnetic moments of both the payload and the solenoid. ${ }^{2}$ In this case, $r$ is the gap between the inside of the solenoid and the surface of the payload.

$$
F=\frac{M \cdot m_{p}}{\mu \cdot r}=\left(\frac{\chi}{4 \mu_{0}\left(a-\frac{d}{2}\right)}\right)(\pi a d B)^{2}
$$

The force on a 50-kg payload is calculated at the throat of the solenoid. The induced magnetic moment $\left(\mathrm{m}_{\mathrm{p}}\right)$ on the payload of diameter $\mathrm{d}$ is calculated by multiplying the magnetic field flux density $\mathrm{B}$, the absolute permittivity of the iron $\chi$, the magnetic permeability of the iron $\mu$, and the cross-sectional area of the payload. ${ }^{2}$

The magnetic moment of the solenoid (M) is taken to be that at the entrance to the solenoid of radius $a$. Formula (4) assumes that the payload is near the center of the solenoid, thus its relative angle is near to $90^{\circ}$.

$$
M=\pi a^{2} \frac{B}{\mu_{0}}
$$

The primary constraint on the number of payloads that can be captured and redirected by the L1 station is the acceleration being imparted on the individual payloads and the station should be designed to reflect this. Depending

American Institute of Aeronautics and Astronautics 
on the strength of the iron used to construct the hollow iron payloads, they may not be able to withstand the force applied by the solenoid. Two possible solutions exist to this problem. One solution is multiple solenoids operating on different payloads simultaneously. Another solution is to increase the mass of the payloads above the $50 \mathrm{~kg}$ proposed here. For the purposes of this paper, $100 \mathrm{~g}$ is assumed to be the maximum acceleration.

Using 1D kinematics, an acceleration of $94.8 \mathrm{~g}$ would need 5.4 meters and 0.108 seconds to slow a $50 \mathrm{~kg}$ payload from $100 \mathrm{~m} / \mathrm{s}$ to zero relative velocity. That indicates that the solenoid will need to be about 5.4 meters long. All the above calculations apply to a solenoid with a 5-meter diameter, 200 turns, and 360-amp power supply. At 124 VDC, the station in its initial configuration could support two of these.

The numbers in Table 1 represent a space station with a 100-kW power supply from its solar arrays. As solar panels are sent up from the lunar surface, some should be retained for construction of additional solar arrays for the station. Additionally, twin constellations of solar power satellites like the ones being placed at GEO could be set up at L4 and L5 to generate and transmit power to the L1 station. Thus, the periodic eclipses would be less disruptive to the station's operations.

The act of slowing payloads launched up from the lunar surface as well as "juggling” them in their respective halo orbits will impart momentum on the space station. The station's halo orbit will need to be maintained, either with chemical thrusters or with ablative laser thrusters like those used on the tugs. Chemical thrusters would need to be refueled, so the ablative laser thrusters are more desirable over the long term.

5. Transfer to GEO

According to Phipps et al. ${ }^{28}$, an electrodynamic hybrid ablative laser thruster using alumina can produce up to 6000 seconds of specific impulse $\left(\mathrm{I}_{\mathrm{sp}}\right)$. There is a wide range of values for the specific impulse that can come from an ALP thruster. 6000 seconds and 500 seconds were taken as the bounds for the specific impulse which were then to estimate how much slag ablator would be needed to move a $50 \mathrm{~kg}$ spacecraft from L1 to GEO. This plot assumes $685.05 \mathrm{~m} / \mathrm{s}$ of $\Delta \mathrm{v}$ required to move from Earth-Moon L1 to GEO. Naturally, it would make sense to attempt to reuse the lasers and guidance system on the tugs. They could use the same ALP system to send themselves back to the L1 station for reuse, using the remaining ablator material. The ablator material would be replaced as needed at the L1 station. The transfer from Earth-Moon L1 down to GEO would likely take several weeks, given a constant thrust.

Assuming no plane changes are involved, a constant retrograde thrust from L1 to GEO would require a $\Delta \mathrm{v}$ that is simply the difference in orbital velocities from L1 to GEO. The semimajor axis of L1 relative to Earth was taken as $652,780 \mathrm{~km}$. With L1's effective orbital period being identical to that of the Moon, the station at L1 would complete one full orbit around the Earth approximately every 29 days. The result of this is an effective orbital velocity about the Earth of $868.8 \mathrm{~m} / \mathrm{s}$, approximately $250 \mathrm{~m} / \mathrm{s}$ slower than if the station was orbiting the Earth at that altitude outside of a Lagrange point. The tugs carrying the lunar-launched payloads down to GEO would appear from above the plane of their orbits to be spiraling in toward the Earth. Travel time could take as much as 10 weeks, but this is entirely dependent on the thrust provided and the mass of the payload. For example, a thrust of $0.09 \mathrm{~N}$ exerted on a vehicle of mass $747 \mathrm{~kg}$ would result in a transfer time of 66 days. Transfer time on a constant-thrust trajectory is found by dividing the $\Delta \mathrm{v}$ required over the thrust being applied.

Figure 5: Path from Earth-Moon L1 to GEO

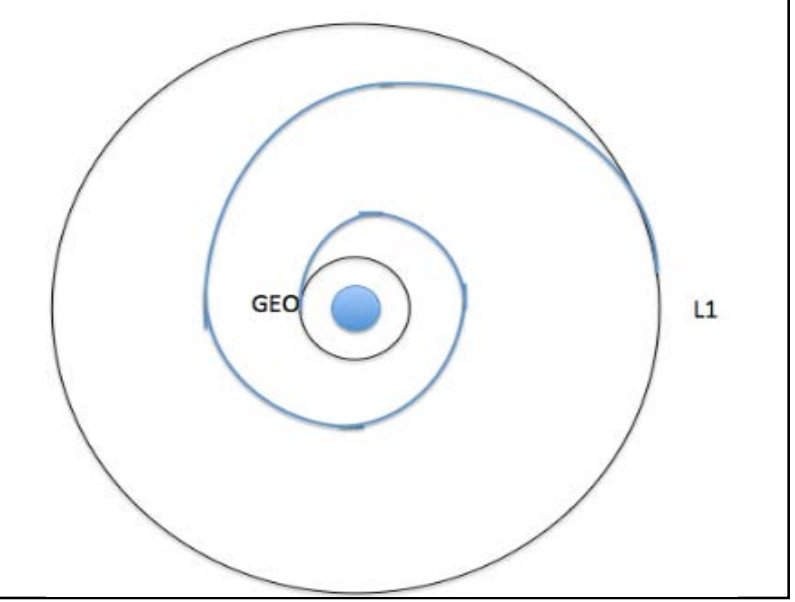

Table 1: Time and distance to slow down payloads from lunar launch.

\begin{tabular}{|l|c|}
\hline Solenoid length (m) & 5.4 \\
\hline Solenoid diameter (m) & 5 \\
\hline Number of turns & 200 \\
\hline Current required (A) & 360 \\
\hline Force of solenoid (kN) & 46.5 \\
\hline Acceleration on payload (m/s $\left.\mathrm{s}^{2}\right)$ & 930.2 \\
\hline Time for slowing (s) & 0.108 \\
\hline
\end{tabular}




\section{Results}

\section{Moon Base Energy}

Solar panels power the lunar base, the infrastructure to mine resources, and the launches of payloads via Gauss cannon. Therefore, an energy storage choice with a low weight and high capacity is desired. In this lunar base, the estimated power consumption for the base is $100 \mathrm{~kW}$. This consumption rate is based on the current International Space Station power consumption model which is between $84 \mathrm{~kW}$ and $120 \mathrm{~kW} \cdot{ }^{29}$ Since the first lunar moon base is constantly exposed to sunlight, a solar panel only system is sufficient provided the solar panels track the sun's movement or are fed with movable reflectors. The $100 \mathrm{~kW}$ power consumption will provide life support, lighting, communication, experiments, computers, food storage, etc, but does not include the Gauss cannon, and mining machinery. The estimated power consumption for the Gauss cannon is to be $2.1 \mathrm{MW}$ and the mining machinery to be $1 \mathrm{MW}$. The overall power needed by each moon based is at least 3.21 MW.

1. Space-rated Solar Panels

The space rated solar panels used for calculations were the XTJ Prime by Spectralab. ${ }^{30}$ The efficiency of the solar cell is $30.7 \%$ of the AM0 $\left(135.3 \mathrm{~mW} / \mathrm{cm}^{2}\right)$ which is one of the highest efficiency solar cells available for production. This gives a theoretical power of $415.37 \mathrm{~W} / \mathrm{m}^{2}$ at a mass of $2.06 \mathrm{~kg} / \mathrm{m}^{2}$ and volume of $6.78 \mathrm{E}-05 \mathrm{~kg} / \mathrm{m}^{3}$. However, the real power output would be slightly lower due to the loss in efficiency as a solar panel reaches its end-of-life usage. In order to power the lunar facility at the base $3200 \mathrm{~kW}$ power load (consisting of life support systems, communication, food storage, lighting, computers, Gauss cannon, and mining machinery), 3082 solar panel units totaling $20033 \mathrm{~kg}$ in mass are necessary at their given power and efficiency assuming the area of the solar panel will be illuminated by sunlight 24 hours a day. With inspiration from the powersat construction of 'a solar tin can' design, ${ }^{31}$ solar panels can be arranged around a central location such as Mt. Malapert with a combination of solar reflectors concentrating sunlight on to the panels at all times and angles using microelectromechanical systems (MEMS) mirrors. The microelectromechanical systems or MEMS are small mirrors controlled by applying a voltage between electrodes in the mirror arrays for light deflection. ${ }^{32}$ This technology is used in digital light processing display (DLP) devices in the movie theater or cinema. This would allow more accurate reflection of light allowing for the control the direction of reflection.

\section{Ultracapacitors (UC) / Supercapacitors (SC)}

Space missions are surrounded by radiation and which affects unprotected electronics and electrical systems. Ultracapacitors (UC) would also be affected by radiation if unprotected. Commercially available capacitors exposed to gamma radiation to simulate space condition show a decrease in capacitance. This decrease is due to ionizing radiation which increases the numbers of free carriers causing a reduction in the number of electric dipoles. ${ }^{33}$ A novel method for ultracapacitor protection in the moon base design allows for the packing of non-space-rated UC's under $2+$ meter of regolith mitigating entirely the need for space-rated ultracapacitors. Using powerful commercial-grade ultracapacitors ${ }^{34}$ allows the use of a high-power Gauss cannon requiring 2.1 MW per payload launch to Earth-Moon L1 orbit. The kinetic energy required to launch a projectile to the escape velocity of the moon $(2264.54 \mathrm{~m} / \mathrm{s})$ is 128 MJ (355.6 Wh). The ultracapacitors must be able to handle the amount of power and energy needed. Calculations were therefore done using the SkelStart Engine Start Module 2.0 UC. Each set of a module has eight 3200 Farad ultracapacitors inside a module holding $35 \mathrm{Wh}$ with a peak power of $109.6 \mathrm{~kW}$. Using this calculation, 20 sets of ultracapacitors could launch a Gauss cannon payload with 8.5 minutes per charge for each UC module should they be charged separately. To decrease the time between lunches, another 18 sets of 20 ultracapacitor modules could fire two launches every minute with current limitations. Optimistically, the number of launches should reach 27 per minute, requiring 243 sets of the 20 ultracapacitor modules.

\section{Space-rated Batteries}

All battery calculations were performed using the GS Yuasa (LSE134) ${ }^{35}$ the choice of a battery because it boasts high specific energy $(\mathrm{kWh} / \mathrm{kg})$. Assuming the energy required to be $100 \mathrm{kWh}$ and the capacity of each battery is 0.496 $\mathrm{kWh}$, then 202 battery units are needed for a mass of $713.1 \mathrm{~kg}$ not including battery management systems, cooling or heating systems, and cables for life support, lighting, and communications systems. Therefore, the total weight will be somewhat greater.

PR is the performance ratio of electrical equipment such as wires, cable, converter, connectors and so on. It includes all system losses, and a typical terrestrial value is $0.75 .{ }^{36}$ To calculate the area of solar panels using the assumption for energy storage in batteries to be $100 \mathrm{kWh}$ a day (the estimated power for the life support system is $100 \mathrm{~kW}$ operating for 1 hour), 24 hours of sunlight illumination and a PR of 0.85, assuming that each device will be optimized. The area of solar panels needed to charge the batteries is $92.55 \mathrm{~m}^{2}$ above the regular baseload for continued usage. Using the area of solar panel needed and a solar panel size of $2.5 \mathrm{~m}^{2}$ each, 38 additional units of solar panels are

American Institute of Aeronautics and Astronautics 
required. Each solar panel weights $5.15 \mathrm{~kg}$ which mean a total additional weight of $195.7 \mathrm{~kg}$. So, the total amount of the solar panels will be 135 units for base operations only.

\section{Space-rated Cable}

The space-rated cable selected and used for calculations is the Gore ${ }^{\circledR}$ power cable due to one of the best weight to protection ratios. The selected cable has different wire gauge size for each power usage (e.g. communication devices require a smaller size wire). The cables have the capability to operate reliably in temperatures ranging from $200 \mathrm{C}$ to $+200 \mathrm{C}$, which is typical for a lunar environment. The cables have a maximum operating voltage of $600 \mathrm{~V}_{\mathrm{RMS}}$ with double layer insulation (Expanded PTFE + polyimide).$^{37}$ There are three variants of the cable that works with different type of usage. The first variant has the biggest wire size of AWG 0, is the heaviest of all the variants standing at 542 $\mathrm{kg} / \mathrm{km}$, and is suitable for high current of 133 A. The second variant has a wire size of AWG 4 with a weight of 232 $\mathrm{kg} / \mathrm{km}$ rated at $81 \mathrm{~A}$. The third variant has the smallest wire size of AWG 8 and has a maximum weight of $98 \mathrm{~kg} / \mathrm{km}$, carrying $45 \mathrm{~A}^{38}$ The variant no. 01 (AWG 0 ) would be best suited for the high current ultracapacitor and the railgun launcher. For other applications which use lower currents, variant no. 3 would be optimal as it is lighter and thinner (AWG 8).

To calculate the cable weight, a geometry for the system must be assumed. For this calculation, the solar panel arrays are assumed to be placed in a circular pattern around the central base. The footprint for the central base is assumed to be circular with a radius of 55 meters. To mitigate the amount of dust that can settle on solar panels, the distance from the base to the solar arrays is assumed to be 110 meters from the center of the base. Another consideration is the number of cables connecting the base to the perimeter. For each ring of solar panels, there will be four cables. Additional perimeters will be spaced 6 meters past the previous line of panels. In each line of panels, 10 panels will be supported on one truss. At least one meter will separate each truss. Furthermore, the panels used are assumed to have a square geometry. For illustration, Figure 6 demonstrates an artistic rendering of this geometry. Combining this information, a cable length and weight can be estimated.

Calculating the minimum cable length is necessary to determine the number of perimeter rings for the solar panels. Using known power requirements 3,082 panels are needed to meet the totality of power requirements for the base. With a given panel area of 2.5 square meters, the panel width can be estimated at 1.58 meters. Knowing that 309

\section{Figure 6: Solar Panel Orientation Around Moon Base Vulcan}

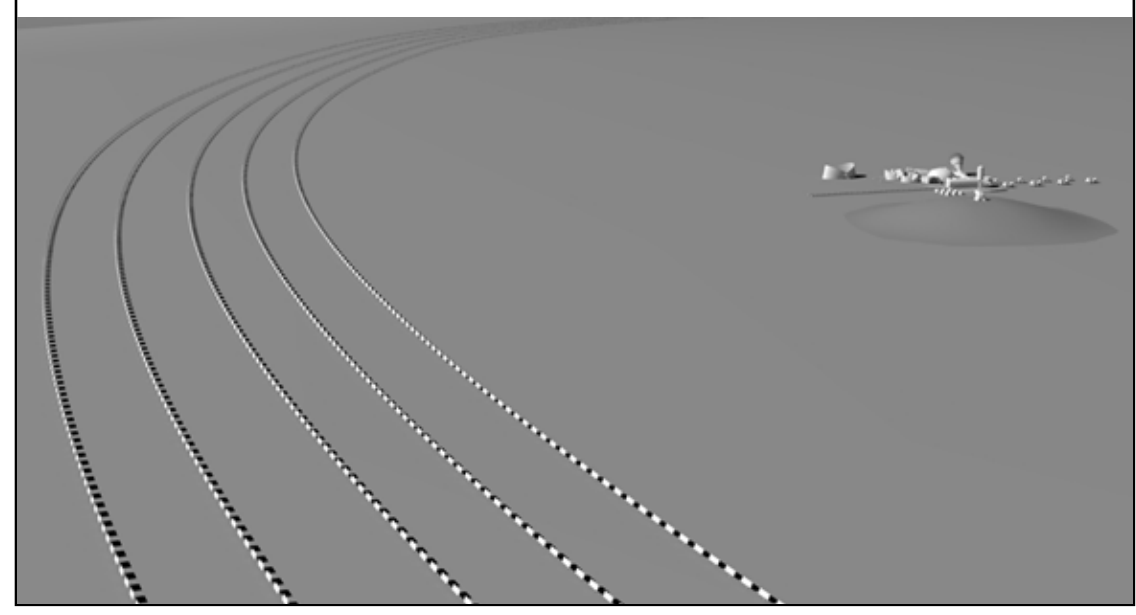

trusses will be used, the minimum cable length needed to connect all the panel arrays in a single line can be calculated as 5180 meters, the minimum cable length needed for the solar array perimeter.

Formula (5) can be used to calculate the cable length required for the assumed base geometry:

$$
L=\sum_{i=0}^{N-1}\left(2 \pi R_{i}+4 r_{i}\right)
$$

In Formula (5), $\mathrm{L}$ is the total cable length, $\mathrm{N}$ is the number of solar array perimeters, $R_{i}$ is the radius from the center of the base to the solar array perimeter, and $r_{i}$ is the distance from the outside of the base to the solar array perimeter. With each iteration of the summation, both radii increase by the distance between each solar panel perimeter (in this case 6 meters). Using the fewest number of perimeters ( 5 solar array perimeters), the total cable length can be calculated at a maximum of 5,173 meters. Given how close this perimeter length is to the needed length, it can be implied that adding a minimal length to a perimeter will allow all panels to fit in 5 solar array perimeters with a total length of 5180 meters.

Using this length, cable weight can be calculated by taking the weight per meter for a selected cable. Using the Gore Variant 1 cable at 542 kilograms per kilometer, multiplied by 5.18 kilometers, the cable weight is estimated to be 2,808 kilograms. 


\section{Analysis}

\section{A. Overall economics}

Massive capital expenditures (CAPEX) are necessary for lunar infrastructure to produce multiple powersats. Assuming the production of all facility modules on Earth and launch to a soft landing on the lunar surface, the estimated cost is $\$ 4.125$ billion per lunar facility. This does not include non-recurring engineering expenses for design, test, validation, and packaging. An average of 22 launches per year for five years is derived, comprised of two launches of the NASA Space Launch System (SLS) or SpaceX BFR plus twenty launches of the Falcon Heavy rocket per year for lighter components. Following the initial heavy launch years, three upkeep and supply launches a year tapering off to a single launch of the SLS per year in the latter years of the 20-year period should be enough to resupply the operation. At this rate, a lunar base as described in this paper can be assembled and operational on the lunar surface within one year. The first SPS can be produced three years later. Following construction of the first powersat in line with Schubert et $\mathrm{al}^{18}$, WPT can provide power to terrestrial customers at a wholesale rate of 3 cents per $\mathrm{kWh}$. At $10 \mathrm{GW}$ gross production, a single SPS can provide $\$ 1.53$ billion in revenue every year after completion. A single launch of the NASA Space Launch System could be valued at $\$ 500$ million ${ }^{39}$ with the Falcon Heavy following at $\$ 90$ million per launch. ${ }^{40}$ Thus, the suggested 2 SLS and 20 Falcon Heavy launches together constitute the average cost of $\$ 2.8$ billion per shipment alone of a lunar facility to the lunar surface.

With current technical limitations considered in this paper alone, the end of a 20 -year period allows 48 powersats with continued production into the future. With these units in place, 7.17 quads of energy enter the grid each year with a predicted 736 quads of global demand by $2040 .{ }^{41}$ With minimal and conservative outlooks from a technological feasibility perspective, $1 \%$ of the global need can be met by powersat production. However, an optimistic perspective on technological advances and solution optimization along with a large financial push early in the ISRU project development allows for a scale-up potential of $22 \%$ of the world's energy demands met by powersats at the end of a 20 -year period. The early financial push involves 4 extra years of 22 rocket launches per year as well as between two and six times the annual upkeep and lunar expansion totaling at 282 rocket launches over the course of 20 years as compared to the 136 rocket launches predicted by the current technical model. However, the revenue estimation of providing $22 \%$ of the world's energy demand is over $\$ 15.2$ trillion. Any advancements in lunar transport mechanisms, ionization, or any technical aspect of this paper provide a shorter timeframe in which SPS production and grid integration can occur, increasing the total percentage of power SPS provides, total revenues, and solving the energy demand problems of the future.

\section{B. ROI Evaluation}

Figure 7: Return on Investment calculations per year of lunar operation.

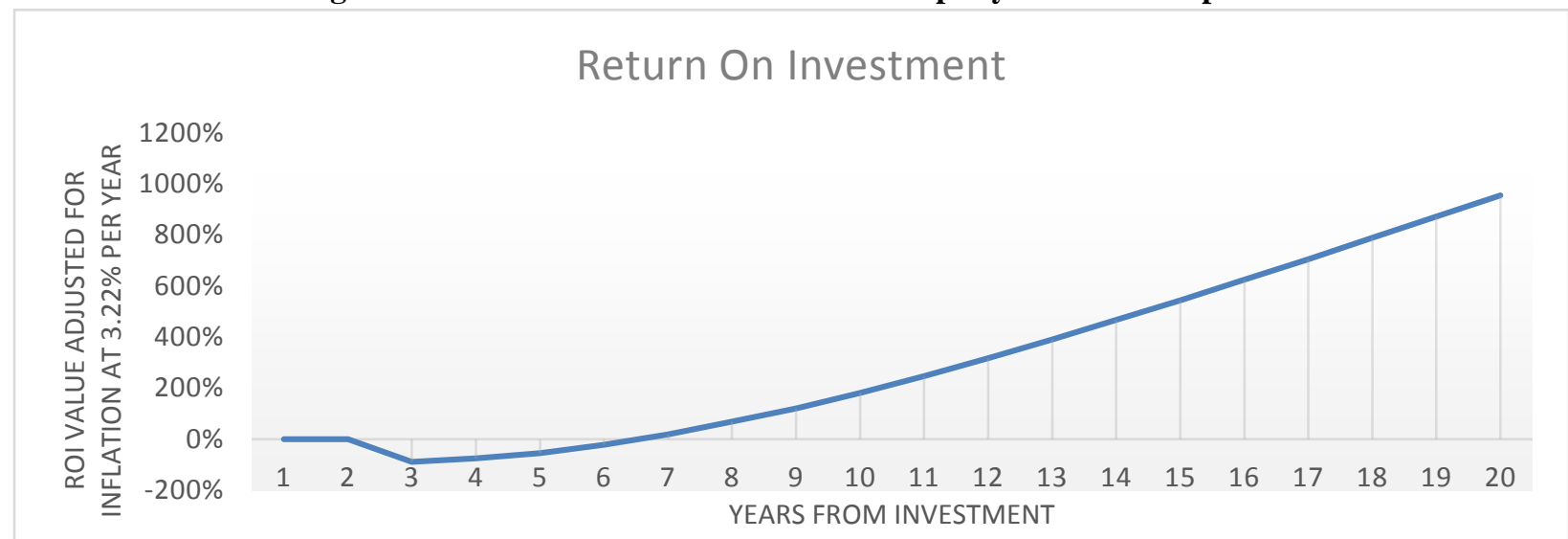

At a $1 \%$ world-energy production rate of expansion using conservative estimates and technically feasible assumptions, a positive cumulative ROI is calculated at the end of the seventh fiscal year post-investment. Furthermore, a steady increase in ROI can be expected in each subsequent year cumulatively. All ROI points assume an inflation rate of $3.22 \%$, the national average over the last 50 years for the USA. ${ }^{42}$ Furthermore, an assumed lack of depreciation in value of lunar structures was assumed due to the novelty of the feats involved. Geometric scale-up performed via an ISRU capability to produce parts and structures allows for continued production and integration to occur on the surface of the moon. However, the fastest way to jump-start revenue is to provide lunar facility parts built on the Earth for use in construction on the lunar surface. The number of pre-built bases assembled on the lunar surface

American Institute of Aeronautics and Astronautics 
directly influences the rate at which SPS production can occur resulting in a nearly geometric powersat production rate with an eventual maturation and low on-going costs once purely ISRU resources are used.

The Present Value (PV) for each year of production provides an in-depth look at the overall investment into lunar structures accounting for powersat production as the sole source of income. From a purely economic perspective, the investment has positive PV 8 years after investment and progressively increases in PV to a potential $\$ 282$ billion by the end of 20 years with an assumed 6\% depreciation rate per year and an inflation rate of 3.22\%. The Net Present Value (NPV) accounting for twenty years of moon base PV and operation is $\$ 1.56$ trillion.

\section{ROI Variants}

\section{Mass Optimization}

To minimize the costs incurred by shipping resources to the moon, it is necessary to determine the minimum mass required to store the energy needed to launch a payload into lunar orbit using the Gauss cannon launch system. Determining this mass will ensure that both the power and energy requirements are met for the railgun while keeping the Earth launch weight as low as possible.

Using the power and energy consumption of the railgun along with specifications for space-rated lithium-ion batteries and ultracapacitors, it is possible to work backward to reach an optimized mass for the system. Figure (8) demonstrates sample calculations for a simple optimization. Figure (8) depicts the lowest theoretical minimum of mass based on a mix of batteries and UC. Although specific values were chosen using current batteries and ultracapacitors, the analysis used is more general and can be used with other specific values depending on the needs of the system.

\section{TOTAL MASS VS. BATTERY MASS [KG]}

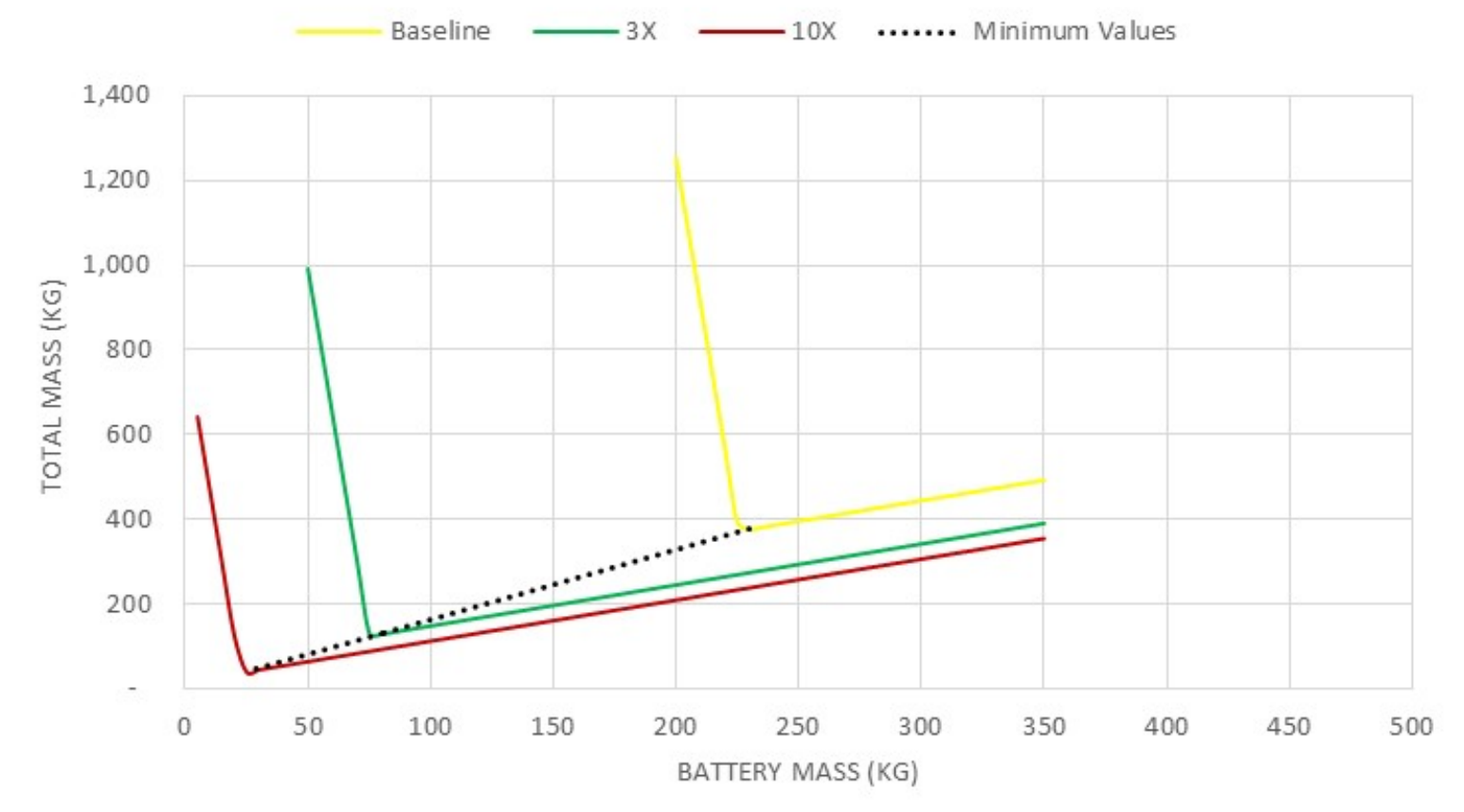

Figure 8: Mass Optimization for Lunar Base Energy Needs

The data used to create Figure 8 was for the given battery and ultracapacitor models powering a 2.1 MW load requiring $128 \mathrm{MJ}$ of energy.

Optimizing the mass of the system begins with identifying the optimum masses in the cases of power and energy requirements. The equations used to perform this optimization specifically focus on the ultracapacitor mass, treating the battery mass as a variable. Equations (6) and (7) demonstrate the ultracapacitor mass needed to meet the power and energy requirements respectively. The values used in these equations are the total mass of batteries in the system, railgun power and energy requirements, specific energy values for chosen ultracapacitors and batteries, and specific power values for the same. After finding ultracapacitor mass values that meet the given requirements for both power and energy of the railgun, the lowest mass that meets both requirements at a given mass of batteries in the system is

American Institute of Aeronautics and Astronautics 
the final mass of ultracapacitors in the system. For example, a mass of $12 \mathrm{~kg}$ is optimized for the power requirements and $25 \mathrm{~kg}$ for the energy requirements (both for a battery mass of $30 \mathrm{~kg}$ ). In this case, the ultracapacitor mass that is needed is $25 \mathrm{~kg}$ because it is the lowest possible mass that can meet both power and energy requirements for the system. Mathematically this process is expressed by Equations (8.1) and (8.2) below. After acquiring the ultracapacitor mass for the system, the total mass needed for energy storage can be given by adding the decided ultracapacitor mass with the battery mass corresponding to that mass, as expressed in Equation (9). To optimize such a system, multiple iterations are necessary. Adjusting the battery mass for the system and calculating the corresponding total mass for the system will yield a minimum mass for the system. This process was used to create Figure 8.

$$
\begin{gathered}
\text { (6) } m_{P}=\frac{P_{R}-m_{B}\left(S P_{B}\right)}{S P_{S C}} \\
\text { (7) } m_{E}=\frac{E_{R}-m_{B}\left(S E_{B}\right)}{S E_{S C}} \\
\text { (8.1) } m_{s c}=m_{E} \text { if } m_{P}<m_{E}, \quad \text { (8.2) } m_{s c}=m_{P} \text { if } m_{P}>m_{E}, \\
\text { (9) } m_{T}=m_{B}+m_{s c}
\end{gathered}
$$

\section{Conclusions}

Launch mass is a primary economic driver when considering architectures for space solar power. Another consideration is the energy required per launch because the end product of a powersat is energy delivered and one hopes for a high multiple of delivered energy to launch energy. Lunar-based ISRU can fundamentally change this calculus if the produced powersat components are many times greater than the landed lunar mass, and if the energy to transport these components to earth orbit is derived substantially from sunlight. Described in this work is a lunar ISRU powersat architecture which brings both of these benefits and results in an economic analysis with an attractive and increasing return on investment, becoming positive in 7-8 years. This study builds upon patented and published subsystems which, when considered with the work herein, presents a complete powersat architecture capable of providing up to 22 percent of terrestrial power by 2040 at a wholesale rate significantly lower than current energy prices from traditional sources. Because powersats deliver baseload power, they have an advantage over intermittent sources such as terrestrial solar and wind power, even though such renewable sources may have lower costs per kWh. Baseload powersats put no demand on the electric grid for large-scale storage and are amenable to terrestrial facilities which work continuous operations such as manufacturing, recycling, water filtration, electric or hydrogen transportation, and other valuable services to sustainable living for mankind on earth. Furthermore, the generation of large-scale power in orbit, combined with far-field wireless power transfer, enables an entire cislunar transportation infrastructure which can support large populations, industrial and research facilities, lunar bases and habitats, and even processing facilities for extracting valuable resources from asteroids. Lunar-sourced powersats represent an invaluable foundation for terrestrial, lunar, asteroidal, Martian, and space operations with many benefits and markets created and made more sustainable.

American Institute of Aeronautics and Astronautics 


\section{References}

${ }^{1}$ Schubert, P., US 6,930,304, "Process and Apparatus for Isotope Separation in a Low-Gravity Environment,” 2005

2 Schubert, P., "Synergistic Construction Mechanisms for Habitats in Space Environs," Int'l. Space Development Conference 2006, Los Angeles, CA 2006

${ }^{3}$ Schubert, Peter J. Isotope separation process and apparatus therefor. US Patent US7462820 B2, filed March 10, 2004, and issued March 10, 2005.

${ }^{4}$ Schubert, P., et al, US 7,935,176, “OXYGEN EXTRACTION APPARATUS AND PROCESS,” 2011.

${ }^{5}$ Schubert, P., US 6,994,296, "APPARATUS AND METHOD FOR MANEUVERING OBJECTS IN A LOW/ZERO GRAVITY ENVIRONMENT,” 2006.

${ }^{6}$ Iwamoto, J., T. Takeda, and Y. Sato. "Interventions to prevent bone loss in astronauts during space flight." The Keio Journal of Medicine 54, no. 2 (June 2005): 55-59. doi:10.2302/kjm.54.55.

${ }^{7}$ Taranovich, Steve. "International Space Station (ISS) Power System." EDN. Accessed April 08, 2018. https://www.edn.com/design/power-management/4427522/International-Space-Station--ISS--power-system.

${ }^{8}$ Malik, Tariq. "Population in Space at Historic High: 13." Space.com. Accessed April 08, 2018. https://www.space.com/6503-population-space-historic-high-13.html.

${ }^{9}$ Calle, C.I., C.R. Buhler, M.R. Johansen, M.D. Hogue, and S.J. Snyder. "Active dust control and mitigation technology for lunar and Martian exploration." Acta Astronautica 69, no. 11-12 (2011): 1082-088. doi:10.1016/j.actaastro.2011.06.010.

${ }^{10}$ Seedhouse, E., Mars via the Moon: The Next Giant Leap, Springer, 2016 ISBN 978-3-319-21887-8

${ }^{11}$ Toro, C., \& Lior, N. (2017). Analysis and comparison of solar-heat driven Stirling, Brayton and Rankine cycles for space power generation. Energy, 120, 549-564. DOI: 10.1016/j.energy.2016.11.104

${ }^{12}$ Iverson, B.D., T.M. Conboy, J.J. Pasch, and A.M. Kruizenga. "Supercritical $\mathrm{CO}_{2}$ Brayton cycles for solar-thermal energy." Applied Energy 111 (2013): 957-70. doi:10.1016/j.apenergy.2013.06.020.

${ }^{13}$ Higashi, K., S. Nakasuka, T. Himeno, M. Ogawa, Y. Hori, and H. Tanabe. Wankel rotary engine. US Patent US20110126794A1, filed August 01, 2008, and issued June 02, 2011

${ }^{14}$ Heiken, G., D. Vaniman, and B. M. French. 1991. The Lunar Sourcebook: a user's guide to the moon. n.p.: Cambridge [England]; New York: Cambridge University Press, c1991., 1991. IUCAT IUPUI (library catalog), EBSCOhost (accessed February 24, 2018).

${ }^{15}$ Meyer, C. The Lunar Petrographic Educational Thin Section Set. Houston, TX: NASA, 2003.

${ }^{16}$ Cannon, R. "NASA Robotic Mining Competition." NASA. April 16, 2015. Accessed February 26, 2018. https://www.nasa.gov/offices/education/centers/kennedy/technology/nasarmc.html.

${ }^{17}$ Schubert, P.J., Williams, J., Bundorf, T., Di Sciullo-Jones, A., “Advances in Extraction of Oxygen and Silicon from Lunar Regolith,” AIAA SPACE 2010, Anaheim, CA, 30 Aug -2 Sept 2010.

${ }^{18}$ Schubert, P.J., Pinto, S.M., Pires, B.C., do Nascimento, M., Barks, E., Nderitu, J., Goncalves, G., Tokmo, F., “Analysis of a Novel SPS Configuration Enabled by Lunar ISRU," Proceedings AIAA SPACE 2015, Pasadena, CA, 31 Aug. - 2 Sept. 2015.

${ }^{19}$ Schubert, P., US 7,118,075, "SYSTEM AND METHOD FOR ATTITUDE CONTROL AND STATION KEEPING”, 2006

${ }^{20}$ VSim. Program documentation. Version 8.2.1. Ion Thruster (ionThrusterT.pre). Accessed Fall 2017.https://www.txcorp.com/images/docs/vsim/latest/quick_start/VSimPD/RealWorldT/ionThrusterT/ionThrus terT.html.

${ }^{21}$ United States. National Bureau of Standards. Ionization potentials and ionization limits derived from the analyses of optical spectra. By Charlotte Emma Moore. Washington, D.C.: U.S. Dept. of Commerce, National Bureau of Standards, 1970. 2-5.

${ }^{22}$ Crawford, I.A. "Lunar resources." Progress in Physical Geography39, no. 2 (2015): 137-67. doi:10.1177/0309133314567585.

${ }^{23}$ Hoskins, W. Andrew, Et al. "NEXT Ion Propulsion System Production Readiness." 1-16. Proceedings of $43^{\text {rd }}$ AIAA/ASME/SAE/ASEE Joint Propulsion Conference \& Exhibit. Cincinnati, OH: AIAA, 2007

${ }^{24}$ Duncan, S., Schubert, P., Delaurentis, D., "System for Electromagnetic Capture of Lunar-launched Payloads into GEO,” 43rd AIAA/ASME/SAE/ASEE Joint Propulsion Conference, Cincinnati, OH 8-11 July 2007. Accessed October 20, 2017.

${ }^{25}$ Zimovan, E. M., Howell, K. C., Davis, D.C., "Near Rectilinear Halo Orbits and Their Application in Cis-Lunar Space,” AAS, IAA-AAS-DyCoSS3-125, 
https://engineering.purdue.edu/people/kathleen.howell.1/Publications/Conferences/2017_IAA_ZimHowDav.pdf. Accessed November 15, 2017.

${ }^{26}$ Shneerson, German A., et al. Strong and Superstrong Pulsed Magnetic Fields Generation, Walter de Gruyter GmbH, 2014. ProQuest Ebook Central, https://ebookcentral.proquest.com/lib/iupuiebooks/detail.action?docID=893512. Accessed January 31, 2018.

${ }^{27}$ Schubert, P., Simpson, N., Lin, M., “Technical Feasibility of a Novel Method for Station Keeping,” AIAA SPACE 09, Pasadena, CA, 14-17 Sept 2009.

${ }^{28}$ Phipps, Claude and Birkan, Mitat and Bohn, Willy and Eckel, Hans-Albert and Horisawa, Hideyuki and Lippert, Thomas and Michaelis, Max and Rezunkov, Yuri and Sasoh, Akihiro and Schall, Wolfgang and Scharring, Stefan and Sinko, John, "Review: Laser-Ablation Propulsion.” Journal of Propulsion and Power, 2010, Vol. 26, No. 4, pp 609-637. doi: 10.2514/1.43733. Accessed October 20, 2017.

${ }^{29}$ Garcia, M. "About The Space Station Solar Arrays". NASA, 2017. https://www.nasa.gov/mission_pages/station/structure/elements/solar_arrays-about.html.

${ }^{30}$ Spectrolab. XTJ Prime. Sylmar: spectrolab. Accessed 21 January 2018. http://www.spectrolab.com/DataSheets/cells/XTJ_Prime_Data_Sheet_7-28-2016.pdf.

${ }^{31}$ Schubert, Peter J., Sheylla Monteiro Pinto, Bruna Caroline Pires, Moises do Nasicmento, Edward Barks, Jonathan Nderitu, Gabriel Goncalves, and Faith Tokmo. Analysis Of A Novel SPS Configuration Enabled By Lunar ISRU. Ebook. Indianapolis: IUPUI. Accessed 21 January 2018. https://scholarworks.iupui.edu/bitstream/handle/1805/11336/Schubert_2016_analysis.pdf?sequence=1\&isAllowe $\mathrm{d}=\mathrm{y}$

${ }^{32}$ Kalaivani, C., Kumar, S., \& Ramesh, R. (2016). Design and Comparison of Electrostatically Actuated Micromirror with Different Aspect Ratio. International Journal of Innovation and Scientific Research, 23(1), 158-164. Retrieved February 6, 2018, from http://www.ijisr.issr-journals.org/abstract.php?article=IJISR-16-050$\underline{09}$

${ }^{33}$ Ferreira, E. Dos Santos, and J. Sarango Souza. "Gamma radiation in ceramic capacitors: a study for space missions." Journal of Physics: Conference Series911 (2017): 012004. Accessed February 6, 2018. doi:10.1088/1742-6596/911/1/012004.

34 "Ultracapacitor-Based Space Technology That Starts Your Engine". Skelstart.Com, 2017. http://www.skelstart.com/wp-content/uploads/2017/03/170308-SkelStart-24V-brochure.pdf

${ }^{35}$ GS Yuasa. Lithium Ion Cells For Satellites- Power Optimized. Reprint, Roswell: gsyuasa-lp, 2017. http://s399157097.onlinehome.us/sites/default/files/downloads/GS_Yuasa_LSE_GEN_III_\%20Power_\%26_Ene rgy.pdf.

${ }^{36}$ Dierauf, T., A. Growitz, Sarah Kurtz, Jose Luis Becerra Cruz, Evan Riley, and Clifford Hansen. Weather-Corrected Performance Ratio. Ebook. Golden: National Renewable Energy Laboratory, 2013. https://www.nrel.gov/docs/fy13osti/57991.pdf.

${ }^{37}$ GORE ${ }^{\circledR}$ Space Cables. Reprint, W. L. Gore \& Associates, 2016. https://www.gore.com/sites/g/files/ypyipe116/files/201604/GORE\%20Space\%20Cables\%20\%20Product\% 20Portfolio_02-10-2016.pdf.

${ }^{38}$ Taranovich, S. "International Space Station (ISS) Power System". Edn, 2014. https://www.edn.com/design/power-management/4427522/International-Space-Station--ISS--power-system.

${ }^{39}$ Kyle, Ed. "NASA's Space Launch System." Space Launch Report. September 16, 2010. Accessed February 24, 2018. http://www.spacelaunchreport.com/sls.html.

40 "Elon Musk Will Launch SpaceX's Falcon Heavy Rocket At a Cost | Money." Time. Accessed February 24, 2018. http://time.com/money/5135565/elon-musk-falcon-heavy-rocket-launch-cost/.

41 "EIA: World energy consumption to increase 28\% by 2040." Oil \& Gas Journal. September 14, 2017. Accessed February 24, 2018. http://www.ogj.com/articles/2017/09/eia-world-energy-consumption-to-increase-28-by2040.html.

${ }^{42}$ McMahon, T. "Annual Inflation Rate Chart." Rate Chart. February 14, 2018. Accessed February 24, 2018. https://inflationdata.com/Inflation/Inflation/AnnualInflation.asp.

${ }^{43}$ Schubert, P., “A Novel Method for Element Beneficiation Applied to Solar Panel Production,” Space Exploration 2005, Albuquerque, NM. 